\title{
Circular Economy and Its Relevance for Improving Food and Nutrition Security in Sub-Saharan Africa: the Case of Ghana
}

\author{
Emmanuel Kwesi Boon ${ }^{1}$ - Samuel Weniga Anuga ${ }^{2,3}$
}

Received: 31 March 2020 / Revised: 19 June 2020 / Accepted: 29 June 2020 / Published online: 15 August 2020

(C) The Author(s) 2020

\begin{abstract}
Many countries in the world, especially in Sub-Saharan Africa (SSA), are battling with fundamental sustainable development challenges such as widespread poverty, hunger, food and nutrition insecurity and limited access to vital social services like education and healthcare. Climate change impacts during the past decades have exacerbated the situation in the region and pushed several policy-makers, researchers and the international community to vigorously search for appropriate development models that can help to effectively fix the problems in a sustainable manner. The concept of circular economy (CE) has received wide recognition as a feasible accelerator of sustainable development in the world. $\mathrm{CE}$ is based on three main principles: controlling finite stock of natural resources and regenerating natural systems; closing loops; and designing out waste. Employing a mixed methodological approach, the paper examines the importance and relevance of the CE model to SSA, with particular reference to Ghana. We also used the multiple $\mathrm{R}$ or $6 \mathrm{R}$ framework (reduce, reuse, refuse, rethink, repair and recycle) to analyse the circularity of six agricultural crops in northern Ghana. The paper assumes that deploying the CE model to Ghana's agricultural sector will result in high efficiency in the exploitation of natural resources, increase in yields, improved quality of agricultural products, enormous environmental benefits and food and nutrition security. A number of challenges in the application of the model to Ghana's agricultural sector are identified and appropriate recommendations provided for fixing them.
\end{abstract}

Keywords Agriculture $\cdot$ Circular economy $\cdot$ Circular agriculture $\cdot$ Food security $\cdot$ Ghana $\cdot$ Nutrition $\cdot$ Productivity $\cdot$ Value chain

\section{Introduction and Background}

The population of Sub-Saharan Africa (SSA) and its environment, agriculture and agricultural value chains are very closely inter-linked. Agriculture is the predominant economic activity in SSA. According to OECD-FAO (2016), on average, the agricultural sector's share in the region's total GDP in recent years was 15\%. The International Monetary Fund (IMF) statistics reveal that more than half of the region's

Samuel Weniga Anuga

samuelanuga@rocketmail.com

Emmanuel Kwesi Boon

ekboon54@gmail.com

1 International Centre for Enterprise and Sustainable Development (ICED), P. O. Box KA 16461, Airport, Accra, Ghana

2 Climate Change and Sustainable Development Programme, University of Ghana, P.O. Box LG 25, Legon, Accra, Ghana

3 Gottfried Wilhelm Leibniz Universität Hannover, Hannover, Germany labour force is employed in the agriculture sector. In rural areas, the sector provides several livelihood opportunities for multitudes of small-scale producers. Smallholding in these areas constitutes approximately $80 \%$ of their main occupation (FAO 2016; Alliance for a Green Revolution in Africa 2014). The rapidly increasing population growth in SSA and the associated increasing consumption patterns are driving demand for food and the expansion of the agricultural land. Agriculture is suffering from a litany of other challenges including the use of outmoded development models, rural-urban migration, shortage of farm labour, poor infrastructure, inadequate access to finance and markets and negative climate change impacts (Veras 2017; Falola and Mbah 2014). Agricultural productivity levels in most SSA countries like Ghana are insufficient to satisfy the growing demand for food in the region. For many decades, SSA countries like Ghana have not been able to produce sufficient nutritious food to feed the increasing population (Lopes and Kararach 2019; Okoye and FLEAD 2016). Grave economic, social and environmental challenges are the principal consequences of rapid population growth in SSA countries like Ghana. In addition, 
although most of these countries have vast agricultural lands, a booming energetic young population and a tropical climate to support productive farming activities, they are largely dependent on imported food. The severity of the food and nutrition insecurity problem is obvious because by the year 2050, the world population is estimated to reach 9.7 billion and this will lead to an increase in demand for natural resources and agricultural products (FAO 2017; Wijkman and Skånberg 2016). The problem will get worst because most countries of the world mainly rely on the linear economic model which has been dominating the world economic system since the industrial revolution (Ellen MacArthur Foundation 2019). Unfortunately, this model does not take into account the fact that the world's natural resources are finite. The rapid depletion of these resources (land, water, forests and ecosystems) to satisfy increasing demand is creating demand for more sustainably produced alternative products that respect the limits of available resources. Despite improvements in resource efficiency in some SSA countries, the intensification of climate change impacts such as droughts and floods, soil degradation, decrease in arable land and out-migration of the youth from rural areas to urban centres is constraining agricultural productivity and the capacity of most SSA countries like Ghana to produce enough food to feed the surging populations.

\section{The Problem Under Investigation}

Globally speaking, production and consumption of goods and services in most societies continue to follow the linear economy approach which is often referred to as the 'take-makedispose' development model (Ellen MacArthur Foundation 2019). Over the years, the application of this model, which heavily relies on over-exploitation of natural resources to boost global economic growth, wealth creation, consumption and disposal of wastes, is increasingly menacing the earth's life support systems. Although agro-cycle agriculture is the predominant economic activity in SSA, the sector is still underdeveloped and is suffering from outmoded techniques and inadequate infrastructure and finance (Veras 2017; Agrocyle 2017). The productivity levels of the agricultural sector in most SSA countries like Ghana are not sufficient to satisfy the growing demand for food. Consequently, the region is dependent on imported food although it has a vast and extended area for agriculture, a booming young population and a tropical climate to support food production. Another fundamental difficulty facing SSA countries is that modern agricultural practices help to worsen climate change impacts which are increasingly hindering the possibility to feed the population (Swilling 2019; Parry 2019). For example, higher temperatures and changes in precipitation patterns in northern Ghana are causing a reduction in crop yields and the proliferation of weeds and pests on agricultural lands (Kyei-Mensah et al. 2019). With the increasing population growth and expansion of the middle classes, food production is expected to increase by $50 \%$ by 2050 thereby increasing greenhouse gas (GHG) emissions (Veolia 2018).

Presently, climate variability is the main cause of short-term fluctuation in rain-fed agriculture production in SSA and South Asia and other developing regions (Swilling 2019; Parry 2019). In addition, unsustainable agricultural practices have depleted the region's natural resources over the years. For example, SSA's soils are largely unhealthy due to years of nutrition mining and limited use of organic or inorganic fertilisers. According to the World Bank (2013), over $80 \%$ of Africa's agricultural lands are degraded and are estimated to affect 485 million Africans and this costs the continent nearly US\$9.3 billion annually. World Food Programme (2019) indicated that 821 million people in the world - one in nine - still go to bed on an empty stomach each night and worst of all, one in three suffer from some form of malnutrition. SSA is the region with the highest prevalence of hunger. One person in four is undernourished (Food Aid Foundation 2019). High unemployment, poor working conditions, poverty, food and nutrition insecurity, social vulnerability, widening inequalities and inter- and intra-generational inequities have become endemic problems in most SSA countries like Ghana (Boadi and Owusu 2019; Adzawla and Kane 2019). In addition, climate change impacts are exacerbating the problems of low agricultural productivity and hunger in most SSA countries like Ghana. Therefore, eradicating hunger and malnutrition is one of the great challenges of SSA countries (World Food Programme 2019). Huge resources and time are invested in food production but a significant proportion is wasted. According to FAO (2016), about one-third of the food produced in the world for human consumption every year-approximately 680 billion tonnes - gets lost or wasted. Food losses and waste amount to roughly US\$ 680 billion in the industrialised countries and US\$ 310 billion in developing countries. Food waste in developed countries is estimated (222 million tonnes) annually, almost equal to the total net food production of SSA (230 million tonnes). In the developing countries, $40 \%$ of food losses occur at post-harvest and processing stages, while in the industrialised countries, more than $40 \%$ of losses happen at the retail and consumer levels. In SSA, the estimated waste is roughly $37 \%$ or 120-170 kg/year per capita (FAO 2011). Developing countries like Ghana need to vigorously pursue the implementation of SDG 12 which calls for halving per capita global food waste at the retail and consumer levels and reducing food losses along production and supply chains (UN 2015).

\section{Objectives and Assumptions of the Paper}

The general objective of the paper is to establish the theoretical and practical relevance of the circular economy (CE) model for promoting sustainable development in SSA and Ghana in particular. The paper has three specific objectives. 
The first specific objective is to conduct a comprehensive desk research to establish the relevance of the CE model to improving the efficiency and productivity of Ghana's agricultural sector. Secondly, the paper aims to provide agricultural value chain actors in northern Ghana with relevant information for improving the circularity of agricultural products in the country. In this regard, the value chains of six principal food crops from three different categories are examined to determine their circularity levels. The three categories of key food crops are as follows: (a) cereals (maize, millet, sorghum, rice); (b) tubers (cassava, potatoes and yams); (c) fruits (mangoes, pawpaw, watermelon), (d) vegetables (onions, okra, pepper, salad and tomatoes). The rapid changes in global public opinion and consumer habits and values relating to food systems particularly make this objective pertinent. Thirdly, the paper investigates the extent to which the CE model can help to facilitate poverty reduction and enhance food and nutrition security in three of the five regions in northern Ghana.

\section{Methodology}

\section{The Study Location}

Ghana enjoys a tropical climate with a dry season starting from September to April in the southern part of the country and from October to May in northern Ghana which comprises five regions. The average annual rainfall in Ghana is about $1200 \mathrm{~mm}$ and this should normally be sufficient to grow most of the staple foods in the country. Even the coastal savannah belt of the country, which records the least rainfall, has an average annual rainfall of about $850 \mathrm{~mm}$ (Ghana Meteorological Agency 2016). With the exception of cases of occasional extreme climatic conditions, which lead to the destruction of crops, the amount of rainfall is adequate for most crops but the geographical and seasonal distributions are uneven. Ghana has three principle types of vegetation: the coastal savannah, the forest zone and the northern savannah (Wrigley-Asante et al. 2019; Nunfam et al. 2019).

The geographical scope of the paper covers three of the five regions in northern Ghana (see Fig. 1). The selected regions are Northern Region (NR), Upper East Region (UER) and Upper West Region (UWR). These regions are much drier than the southern part of the country. The vegetation predominantly consists of tropical grassland, especially savannah with clusters of drought-resistant shrubs and trees such as shea trees, acacias and baobabs (see Fig. 2). Deforestation, overgazing and periodic drought have caused desertification and soil erosion. Due to its proximity to the Sahel and the Sahara, northern Ghana experiences severe climate change impacts. It is characterised by increased temperatures and variability in rainfall patterns that cause frequent devastating droughts and floods. According to Nkrumah et al. (2014), it is the driest part of the country and receives $150-250 \mathrm{~mm}$ of rainfall per month during the peak months of the wet season (July to September). The area experiences a mean annual temperature of about $29{ }^{\circ} \mathrm{C}$ with daily variations during the mornings. At night, humidity averages $95 \%$ and drops to about $70 \%$ during daytime between April and October. Consequently, during half of the year (December to May), successful crop cultivation requires irrigation to guarantee a good harvest.

Although northern Ghana is endowed with abundant land and water resources, agricultural productivity is very low because of inadequate access to water resources and appropriate technologies as well as finance and markets to ensure all-yearfarming activities (Issahaku and Abdulai 2019). The population of northern Ghana therefore basically depends on rainfall to engage in agricultural production. Many communities in the area face harsh socio-economic conditions due to the severe impacts of climate change and rainfall variability. Besides surface water resources, northern Ghana is endowed with limited groundwater resources, especially the Upper East and Upper West regions (Nyamadi et al. 2012). The Upper West Region alone has about 1.4 million hectares of potential farmlands and a high number of rivers and streams, namely the White/Black Volta, Kulpawn, Sissili, Kulun, Kamba and several others crises-crossing the region. However, these rivers have not been dammed to make harnessing of the runoff water possible. Consequently, the flooding and farmlands and destruction of animals, homes, infrastructure and properties are perennial experiences. The long dry period of 8 months (November to July) significantly affects agricultural production as most farming activities come to a halt. In other words, farming activities are done during only 4 months (AugustOctober) in a year.

\section{Methods and Analysis}

A macro-level (regional) approach was adopted in this study for analysing the circularity of the value chains of the six principal food crops from three different categories of key food crops: (a) cereals (maize, millet, sorghum, rice); (b) tubers (cassava, potatoes and yams); (c) fruits (mangoes, pawpaw, watermelon), (d) vegetables (onions, okra, pepper, salad and tomatoes) from the raw materials stage to the final product stage in three of the five regions in northern Ghana (see Fig. 1). According to Saidani et al. (2019), three main methods for analysing circularity are the Material Circular Indicator (MCI), the Circular Economy Tool (CET) and the Circular Economy Indicator Prototype (CEIP). It is important to note that these methods have their respective advantages and weaknesses. Ghisellini et al. (2016) observed that the current CE literature is still infantile and suffering from important gaps. According to Murray et al. (2017), the lack of integration of the social aspects into $\mathrm{CE}$ is a principal weakness. Circularity can be measured at three different levels: (a) the 
Fig. 1 Map of study locations

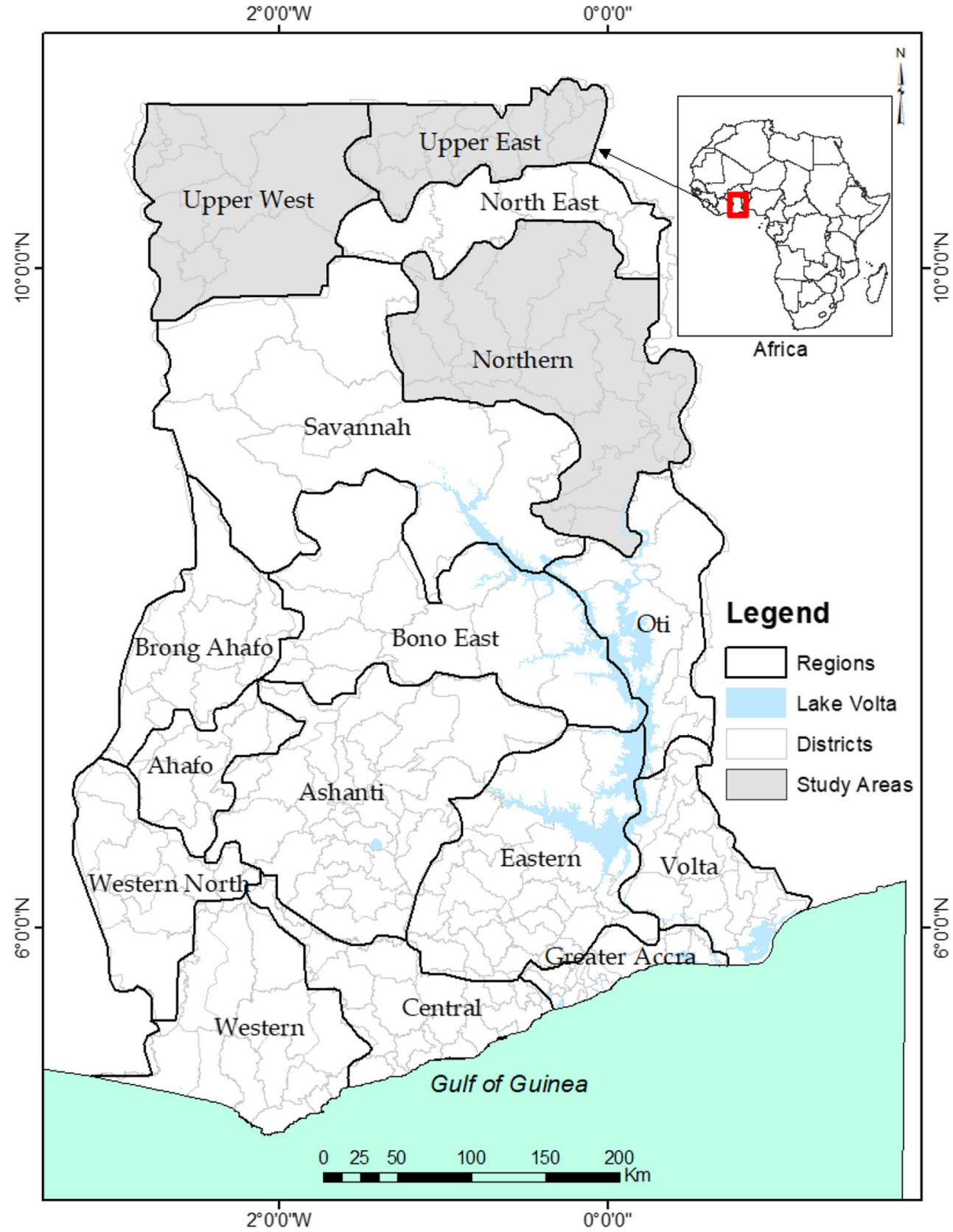

macro-level refers to an investigation at the scale of the city, province, region or nation; (b) the meso-level fits with ecoindustrial parks; and (c) the micro-level corresponds to a single company or consumer investigations. Clearly, this paper opted for the macro-level investigation of three of the five regions in northern Ghana. Considering the infantile state of the application of the CE model in Ghana, this paper opted to use the multiple $\mathrm{R}$ or $6 \mathrm{R}$ (reduce, reuse, refuse, rethink, repair and recycle) framework for collecting information on the circularity of the value chains of selected principal food crops in northern Ghana for analysis and discussion (see Table 1). The 6R framework is embedded in the Ellen MacArthur Foundation's butterfly circular economy model which is used in conjunction with the three dimensions of sustainable development (economic, social and environmental). In addition, elements such as biomass, use of fertilisers, water use, pest management, waste food and waste management are used to determine the circularity of the value chains of the selected six principal food crops. The adopted macro-regional approach will facilitate cooperation, coordination and opportunities for the establishment of regional food hubs in Ghana. The components of the $6 \mathrm{R}$ framework are summarised in Table 1.

The information was collected in two phases. First of all, a comprehensive literature search was conducted to collect relevant information from reports, manuals, research papers, journals, textbooks and Internet sources. The results of the 


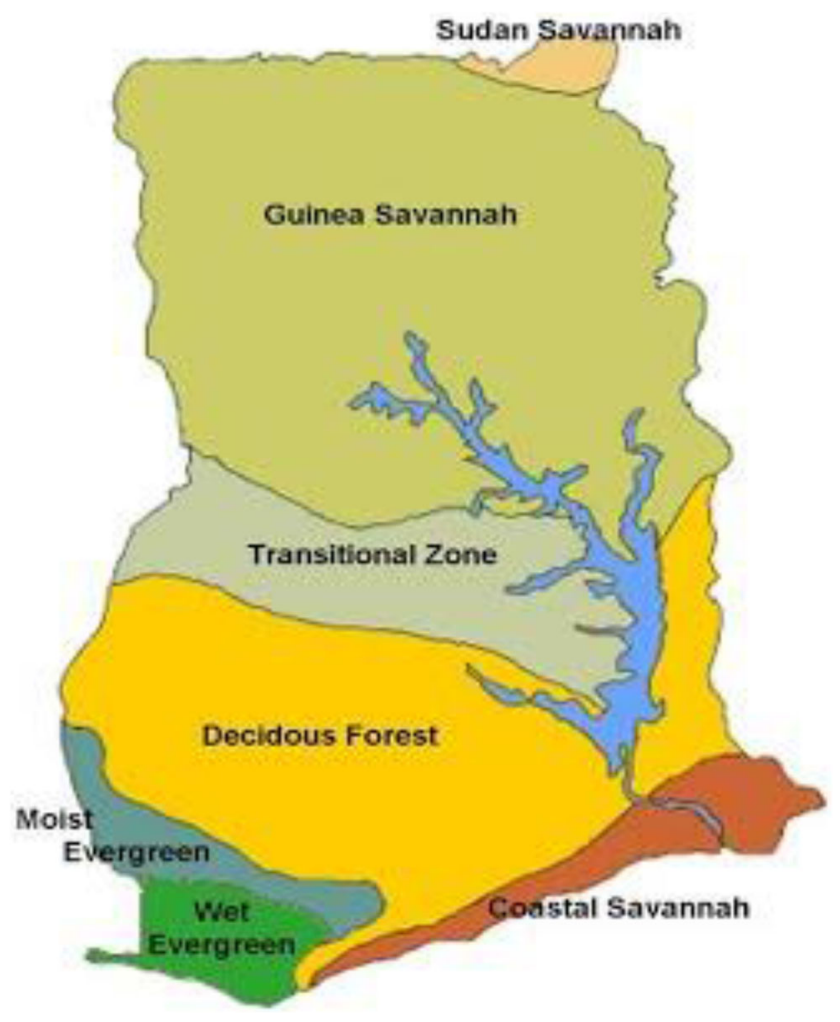

Fig. 2 The vegetation zones of Ghana

literature review informed the design of two field data collection instruments. An interview guide was used to collect information from policy-makers, experts in socio-economic development, agriculture and food systems. Secondly, a structured questionnaire facilitated the collection of information from smallholder farmers and agricultural value chain stakeholders (food sellers, food processors, distributors, traders, consumers, agribusiness entrepreneurs, financial institutions, local authorities, traditional authorities, landowners, researchers and relevant NGO representatives) on the circularity of selected crops. SPSS version 20 and MS Excel 2010 programs were used to analyse the prospects and constraints of the circularity of the value chains of the six crops in the Upper East and Upper West Regions. The results of the data analysis are presented with the help of descriptive statistics such as tables and figures. The qualitative information collected from the actors of the value chains of the investigated three categories of crops was subjected to content analysis and the findings blended with those of the literature review to determine the circularity of agriculture in northern Ghana. The results of the study will help to improve decision-making on transforming the agricultural sector in the country and achieving food and nutrition security and combating poverty reduction in northern Ghana and the country in general.

\section{Conceptual Framework of the Paper: Circular Economy Model}

The disastrous impacts of the linear economy approach catalysed the search for sustainable development models which intensified during the 1990s. The development of the $\mathrm{CE}$ model can be traced back to many years and places in history as well as many authors in China, the USA, Germany and the Club of Rome. However, it is the McKinsey (2016) study on the next evolution in global socio-economics that made the CE concept a reality and a practice for promoting global sustainable economic
Table 1 Explanation of the principles of the $6 \mathrm{R}$ framework

\begin{tabular}{|c|c|c|}
\hline No. & $\begin{array}{l}\text { Principles of the multiple R } \\
\text { (6R) framework }\end{array}$ & Explanation of the principles of the $6 \mathrm{R}$ framework \\
\hline 1 & Reduce & $\begin{array}{l}\text { Reduce represents the endeavour of eco-efficiency in production } \\
\text { (Simone et al. 2000) and consumption. Eco-efficiency is a business } \\
\text { framework and goal that aims at generating value while decreasing } \\
\text { environmental impact (Huppers \& Ishikawa, 005, p. 1) }\end{array}$ \\
\hline 2 & Reuse & $\begin{array}{l}\text { Reuse is the design of products and business models that promotes a } \\
\text { cyclical sequence (Ghisellini et al. 2016). It allows for } \\
\text { re-manufacturing or repairing thereby reducing transportation and } \\
\text { packaging (Stahel 2013). }\end{array}$ \\
\hline 3 & Refuse & Refuse refers to not buying materials and products that are unsustainable. \\
\hline 4 & Rethink & $\begin{array}{l}\text { Rethink relates to current lifestyles and the way we design and make } \\
\text { products. }\end{array}$ \\
\hline 5 & Repair & $\begin{array}{l}\text { Repair implies repairing a product to enable it to be continuously used } \\
\text { instead of throwing it away. }\end{array}$ \\
\hline 6 & Recycle & $\begin{array}{l}\text { Recycle refers to any recovery operation by which waste materials are } \\
\text { reprocessed into products, materials or substances, whether for the } \\
\text { original or other purposes (Ellen MacArthur Foundation 2015; } \\
\text { European Commission 2015; Ghisellini et al. 2016). }\end{array}$ \\
\hline
\end{tabular}

Source: Compiled by Authors, 2019 
development. Since 2009, the Ellen MacArthur Foundation (2013) has focused on educating and supporting CE efforts worldwide. The principal objective was to achieve maximum efficiency in resource use while keeping the production of wastes and pollutants to a minimum. CE has been defined differently by various writers. It is sometimes called the 'reduce-reuse-recycle' model in contrast with the current 'takemake-dispose' model. The most widely known definition of $\mathrm{CE}$ is that of the Ellen MacArthur Foundation:

Looking at the current 'take-make-dispose' extractive industrial model, the circular economy is restorative and regenerative by design. Relying on system-wide innovation, it aims to redefine products and services to design out waste, while minimizing negative impacts. Underpinned by a transition to renewable energy sources, the circular model builds economic, natural, and social capital.

As Fig. 3 depicts, the development of the CE system is a move away from the traditional linear economy model which has not been effective with increasing levels of wastes not being recycled and ending up in landfills, incinerators and open spaces in the environment. CE is a new way to design, make and use things within planetary boundaries (Ellen MacArthur Foundation 2019).

Unlike the traditional linear production ('take-make-dispose') approach that essentially converts natural resources to products and then wastes that are disposed of indiscriminately, the CE model allows circular businesses to 'close the loops' in supply chains by reusing end-of-lifecycle products as raw materials, sharing idle resources, using renewable resources or extending the product lifecycle (Wyman 2017). CE model aims to have no net effect on the environment, to reduce natural resource use and waste production and to effectively reduce the wastes and process them into valuable co-products. The key principles of CE include the 6R framework (reduce, reuse, refuse, rethink, repair and recycle) (Jawahir et al. 2006). It is a mechanism for transitioning growth into positive benefits for the environment, the economy and society. The CE model enhances economic development that 'promotes coordination and harmony of man and nature'. According to the Ellen MacArthur Foundation (2015), the deployment of CE solutions would reduce the world's raw material needs and boost global employment and economic growth.

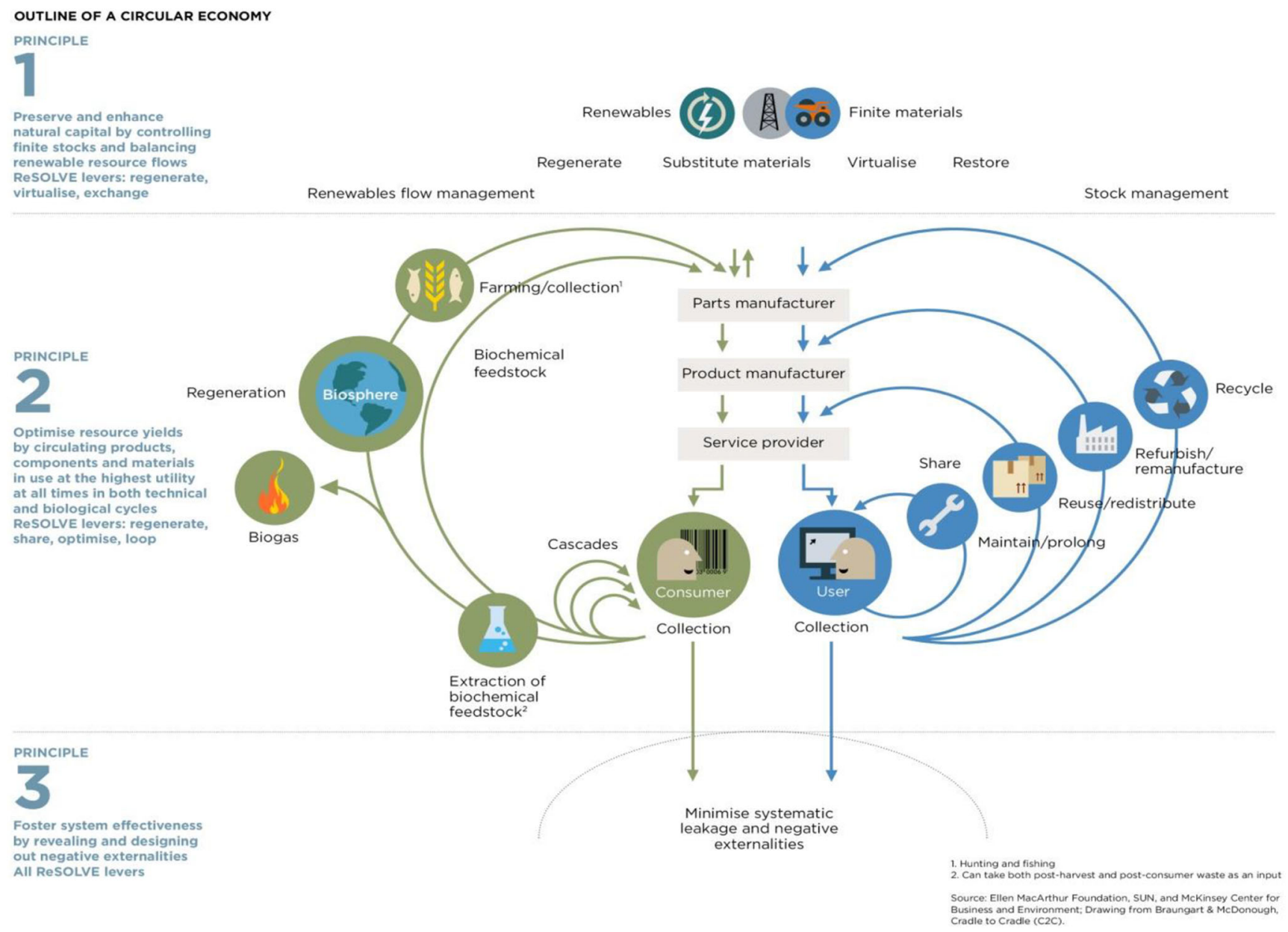

Fig. 3 Outline of a circular economy 
The main idea of CE is that rather than discarding products before the values are fully utilised, we should use and reuse them. Presently, only a small percentage of the original values of products are recovered after use. Decoupling growth from resource constraints is a powerful characteristic of the $\mathrm{CE}$ model. However, Ghisellini et al. (2016) observed that the current $\mathrm{CE}$ literature is still infantile and suffering from important gaps. As is illustrated in Fig. 4, CE starts with the circular design of the main stages of a product's life cycle (Geisendorf and Pietrulla 2017). Transportation should be designed to support circularity at all stages, and the product has to be designed in a way to enable circularity at all stages. This micro-perspective is embedded in meso- and macro-perspectives, which allow realising additional circularity, possibly through synergies. The meso- and macro-levels also require a circular design and coordination and form the core elements of a CE. Surrounding this core are framing conditions enabling the transition to a $\mathrm{CE}$ and considering the feasibility of a project. Measuring the degree of circularity attained by a project requires appropriate tools. The business model perspective investigates feasible initiatives and informs about their profitability. Following is a focus on policies needed to support not (yet) profitable CEBM through laws, infrastructure or financial support. Finally, a project should be checked for its sustainability implications, for example, with regard to social sustainability.

\section{Relevance of Circular Economy to Sub-Saharan Africa}

CE is relevant for SSA countries like Ghana because it promotes the design of products and services that minimise resource depletion, waste and environmental degradation. Furthermore, CE would enable Ghana to reduce her dependence on imports and stimulate economic growth by creating new jobs and spurring the development of green technologies. It will also enable individuals and enterprises to move out of their boxes, create partnerships and learning platforms. In other words, CE provides a framework to challenge and guide society and development actors to reflect and craft appropriate development strategies (WEF 2014). Fortunately, CE principles are already widespread in developing countries like Ghana. Thiaw (2017), Deputy Director for the UN Environment Programme, confirmed the relevance of CE to developing countries at the World Circular Economy Forum in June 2017 thus:

Developing countries are circular economy experts. For instance, shoes are repaired three or four times. Repairing is part of the DNA of developing countries.

During the past few years, some African countries like Rwanda, South Africa and Nigeria are leading the promotion of $\mathrm{CE}$ in the continent. In cooperation with the World Economic Forum and the Global Environment Facility, they launched the African Circular Economy Alliance (ACEA) in 2017 to spur Africa's transformation to a circular economy (da Silva 2018; WEF 2014). The aim of this initiative is to promote economic growth, increase jobs and positive environmental outcomes for Africa. The opportunities CE provides for enhancing industrial symbioses have been highlighted by many experts. The alliance promotes the learning of the best practices and cases of the countries and connects public and private sector leaders from across the continent to drive the $\mathrm{CE}$
Fig. 4 Circular economy framework. Source: Geisendorf and Pietrulla (2017)

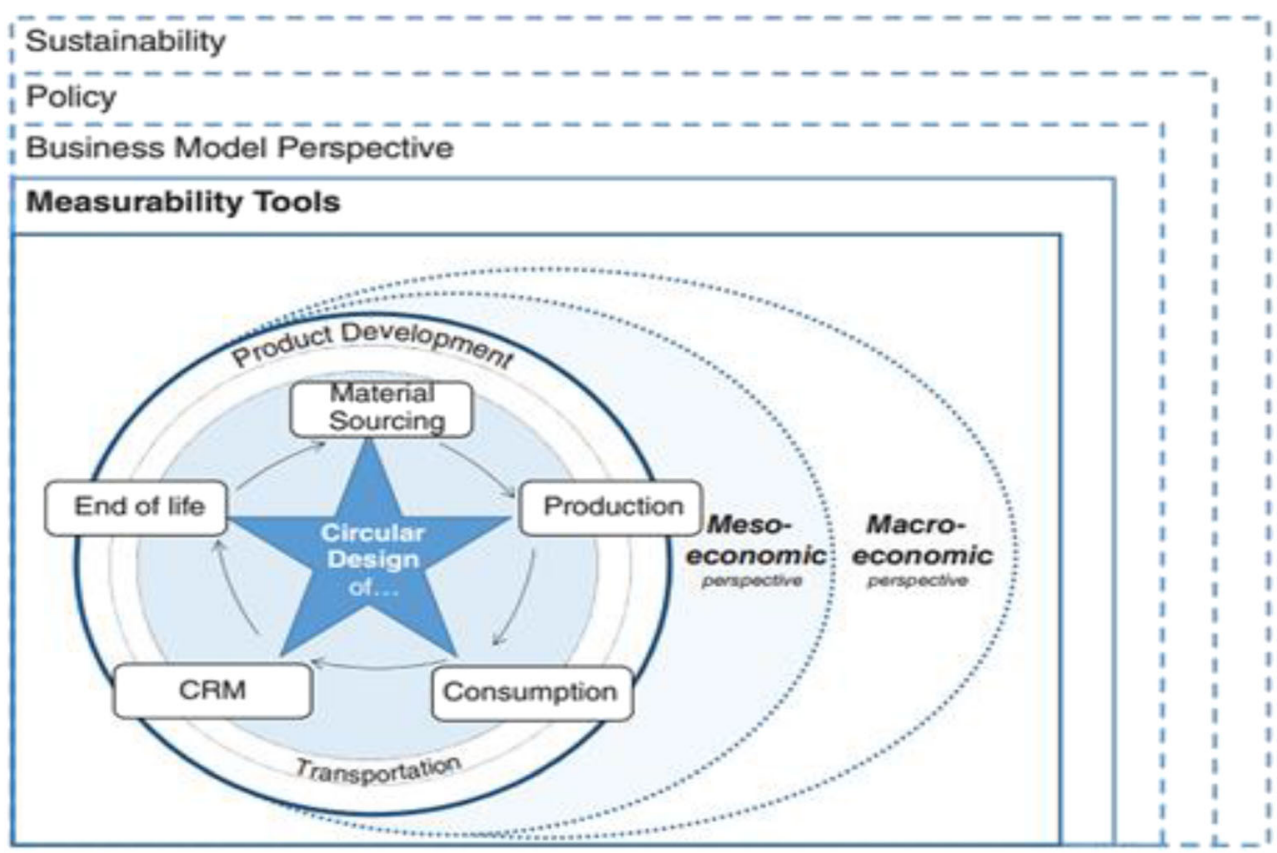


model (Berg et al. 2018; Canning et al. 2015). In addition, an NGO called the African Circular Economy Network (ACEN) has been established to help build restorative African economies that generate wellbeing, prosperity and environmental benefits. Furthermore, an international conference on 'Circular Economy Opportunities in Ghana', which was hosted by the EU at the Labadi Beach Hotel in Accra, Ghana, in February 2019, confirmed the relevance of CE for up-scaling economic opportunities as well as social and environmental benefits for the country (EU 2019). The conference affirmed that transiting to a $\mathrm{CE}$ will enable the values of products, materials and resources to be maintained in the economy for as long as possible, the generation of waste minimised and a more sustainable, low carbon, resource-efficient and competitive economy achieved. The conference therefore recommended that $\mathrm{CE}$ should be an integrated part of the development policy of Ghana.

\section{Requirements for Transiting to Circular Economy}

Significant efforts at the local, national, regional and global levels are required before Ghana can transition to a circular economy. The government, enterprises and the general public need to implement the RESOLVE framework which comprises the following actions: regenerate, share, optimise, loop, visualise and exchange. These actions are summarised below:

a Regenerate: Shift to renewable energy and materials; reclaim, retain and regenerate the health of ecosystems; and return recovered biological resources to the biosphere.

b Share: Allow for maximum utilisation of products through sharing of privately owned products with colleagues or sharing of public products; reuse them through their technical life spans; and prolong those life spans through maintenance, repair and design for durability. Examples include car-and home-sharing business models.

c Optimise: Enhance the performance and efficiency of products; remove waste from their supply chains; and leverage big data, automation and remote sensing. None of these actions requires changing products or technologies.

d Loop: Keep components and materials in closed loops and prioritise the inner ones. For finite materials, this implies re-manufacturing products or components and (as last resort) recycling materials. With renewable resources, anaerobic digestion and biochemical extraction from organic waste is achieved.

e Virtualise: This is through smart systems like virtual offices, online shopping, fleets of autonomous vehicles and utility books or music. f Exchange: Old materials are replaced with renewable ones; new technologies introduced or applied. These actions reinforce and accelerate the performance of others.

\section{Circular Agriculture for Increasing Productivity and Food and Nutrition Security in Northern Ghana}

A feasible way to effectively fix poverty and food and nutrition insecurity in Ghana is to systematically deploy the CE model in agriculture. The application of the model to agriculture is referred to as 'circular agriculture' (CA) which centres on the production of agricultural produce using minimal amounts of external inputs, closing nutrient loops and reducing negative discharges into the environment in the form of wastes and emissions (AgroCycle 2017). CA simply implies the application of the principles of $\mathrm{CE}$ to agricultural production. It is a new concept and an improved approach to agriculture that addresses the needs of populations, resources and the environment in a coordinated way (Lovins 2019). Wageningem University (2018) defines CA as:

Circular agriculture is a collective search by farmers, interested citizens, businesses, scientists and researchers for the optimum combination of ecological principles with modern technology, with new partnerships, new economic models, and credible social services. It not only focuses on good yields and the sparing use of resources and energy, but also stresses the importance of putting as little pressure on the environment, nature and climate as possible.

\section{Key Characteristics of CA}

The characteristics of CA are in line with the concept of extension of product chains and resource conservation. The key tenet of CA is to utilise agricultural biomass often and as effectively as possible. It also implies the avoidance of biomass degradation and the associated production of carbon dioxide, nitrous oxide and methane. CA therefore offers opportunities for reducing GHG emissions in the agricultural sector (Wageningem University 2018). CA combines the best traditional practices with the finest science to deliver abundant, sustainable and high equality life to the world's population (Cheng et al. 2019). Some practices of CA include organic manuring, crop rotation, cover cropping and leguminous crops (Schroeder et al. 2019; Antoniou et al. 2019). In addition, organic agriculture uses bio-diverse systems that focus on a longer view of production, and not maximising yields in any 1 year, but ensuring increasing yields over many years 
and decreasing chances of future crop failures. Farms using crop rotation and animal manure deliver improved biodiversity than fields using industrial practices. Farms that integrate livestock rearing into vegetable production, use of perennial pastureland and organic production deliver higher profitability while creating the circular economy of the soil (Zucchella and Previtali 2019). They also ensure farm workers' safety and investments that sustain farming communities.

According to Lovins (2019), the regenerative economy is dependent on the circular economy of soil, which is one of the key natural capitals both humans and wildlife depend on. Three ways to move towards regenerative agriculture are as follows: (a) return farming systems to harmony with nature's cycles; (b) make and use biochar; and (c) implement holistic management across the world's grasslands. SSA countries like Ghana will gain enormously if they systematically deploy the $\mathrm{CE}$ and $\mathrm{CA}$ models throughout their economies. CA permits optimal allocation of resources and efficient use of wastes and keeps negative environmental impacts to a minimum (Lovins 2019). It is the route to food and nutrition security in northern Ghana. The African Heads of States and Governments' decision at Addis Ababa in 2011 to mainstream ecological organic agriculture into the agricultural systems of all member nations by 2020 is in the right direction (African Union 2015). It is also important to mention that AU's Strategic Plan for the Ecological Organic Agriculture Initiative (OEA) from 2015 to 2025 is a tacit recognition of the huge potential benefits of CA to the continent:

The Ecological Organic Agriculture has experienced encouraging growth over the past few years. The acreage of land in Africa under organic agriculture and the concern for our ecosystems and biodiversity continues to increase.

CA can lead to an extensive restoration of grasslands in northern Ghana and re-establish soil integrity and biodiversity. CA can also contribute to stabilise climatic conditions, restore a balanced hydrological cycle and create meaningful jobs in rural communities (Lovins 2019). It can increase the productivity of smallholder farmers without the use of synthetic fertilisers and promote the circular economy of soils, reestablishing the symbiotic balance between healthy soils and animals.

\section{Results and Discussion}

The literature review findings abundantly indicated that the UN Sustainable Development Goals (UN 2015) were designed to motivate and facilitate the world economies to address major challenges faced by society and the environment (Kapoor et al. 2020; Toop et al. 2017). Relevant to most of the
SDGs is the underlying principle of optimum and responsible usage of resources for purposes leading to a convincing transition to a CE (Antoniou et al. 2019). In most SSA countries like Ghana, ample opportunities exist for transition to CE. This paper examined cross-cutting issues of CE in SSA's agricultural sector using Ghana as a proxy. A number of fundamental challenges are hindering this transition in the country which have been identified and discussed in the paper. Table 2 and Fig. 5 indicate that the lack of understanding of the concept by most agriculture value chain actors is one of the key problems. A majority (63.0\%) of the respondents have not heard of the CE concept. Fifty (50.0) percent hold the view that $\mathrm{CE}$ is relevant to Sub-Saharan Africa while more than half (55.7\%) do not believe that agricultural actors in Ghana can put CE into practice. The fact that $50 \%$ of the stakeholders surveyed did not have any idea about the concept is illustrative of the CA deployment difficulties in the country.

Agricultural value chain stakeholders in Ghana do not have defined CE approaches and/or practices and this implies inadequate knowledge of the concept and potential implementation challenges. The finding that $50 \%$ of the respondents had no idea of what $\mathrm{CE}$ means backs the fact that their knowledge of CE is very low. Few (16.7\%) of the respondents think $\mathrm{CE}$ is merely the avoidance of overdependence on natural resources, reduction of waste production $(13.9 \%)$ and use of composting (11.1\%). Inadequate knowledge and understanding of $\mathrm{CE} / \mathrm{CA}$ may significantly impede an effective deployment of the concepts in the future on agriculture, food and nutrition security and poverty. Understanding of the CE concept is as important as implementing its principles. Growing literature indicates that the linear economic model is still the common practice in most African countries (Secco et al. 2020; Junjie et al. 2011).

However, the majority of the policy-makers and experts of socio-economic development, agriculture and food systems were quite knowledgeable about $\mathrm{CE}$. A representative of the Ministry of Food and Agriculture (MoFA) viewed CE to entail a gradual decoupling of economic activity from the consumption of finite resources and designing waste out of the system. Another expert explained the concept thus:

Table 2 Knowledge and understanding of CE

\begin{tabular}{lll}
\hline CE statements & Yes (\%) & No (\%) \\
\hline Heard of CE concept & 37.0 & 63.0 \\
CE is relevant to Sub-Saharan Africa & 50.0 & 50.0 \\
Agriculture actors can put CE into practice & 55.6 & 44.4 \\
Agriculture actors put CA into practice & 44.3 & 55.7 \\
Agriculture actors understand the principles of CA & 72.2 & 27.8 \\
Agriculture actors effectively practice CA principles & 33.0 & 67.0 \\
\hline
\end{tabular}




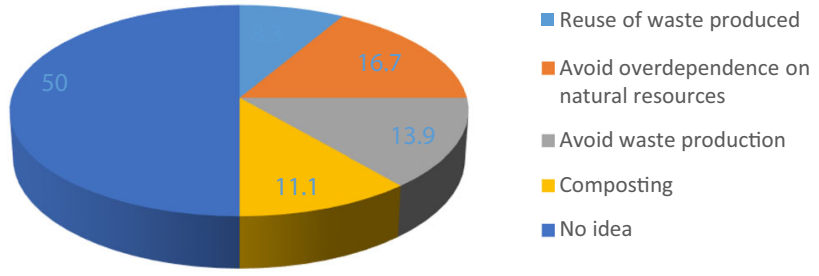

Fig. 5 Respondents' explanation of CE

$\mathrm{CE}$ is looking beyond the current take-make-waste extractive industrial model, a design out waste and pollution. It inculcates strategies to design out waste and pollution, keep products and materials in use and regenerate natural resources. Even though the idea is excellent, the agricultural sector has not yet been able to adopt the principles very well (interviewee 1; Ministry Representative).

In order to verify the extent to which the CA model is being deployed by agricultural stakeholders to achieve socioeconomic development, resource efficiency and environmental protection, the paper used the $6 \mathrm{R}$ (reduce, reuse, refuse, rethink, repair and recycle) framework. As is shown in Table 3 , only reduce (mean $=4.271$ ) was most practised by the surveyed agricultural value chain actors. Reuse (mean = 2.80 ), refuse (mean $=2.36$ ), repair $(2.69)$ and recycle (mean $=$ 2.22) had unsatisfactory performance, whereas rethink $($ mean $=1.88)$ had a poor score. To promote circularity in agriculture, the network of functions from the farmers, marketers and manufacturers to consumers is essential. This will help to reduce the volumes of exiguous or non-renewable resources and materials and production of wastes throughout the life cycle of agro-products. The intensification of agricultural circularity in Ghana mainly focuses on waste reduction. Prevailing cultural norms in rural communities and even among the elite groups constitute a bane to the practice of

Table 3 Application of circular agriculture principles by agriculture value chain stakeholders

\begin{tabular}{llll}
\hline Principles & Mean & Std. deviation & Std. error \\
\hline Reduce & 4.72 & 1.23 & 0.20 \\
Reuse & 2.80 & 1.03 & 0.17 \\
Refuse & 2.36 & 1.15 & 0.19 \\
Rethink & 1.88 & 0.66 & 0.11 \\
Repair & 2.69 & 1.26 & 0.21 \\
Recycle & 2.22 & 0.10 & 0.10 \\
\hline
\end{tabular}

Scale: 1 = poor performance, 2 = unsatisfactory, $3=$ fair performance, $4=$ good performance and $5=$ excellent performance reuse. For example, the reuse of a resource may make one look poor, lazy or foreign in the eyes of the community. Recycling helps the completion of a product and its function to become re-available rather than useless garbage. Practically speaking, recycling is an efficient way to achieve agriculture circularity. However, the deployment of this concept by most agricultural value chain actors in Ghana is severely challenged by a lack of know-how and capacity. An effective mechanism for achieving agricultural circularity in the country is to develop and implement appropriate policies and strategies that prevent waste and negative climate change impacts (Hanumante et al. 2019; Xi 2011).

At the farm level, we tracked already existing CA practices among rural farmers. The outcome indicates that some forms of CA innovations are being employed by farmers but at a lower scale. The CA innovations were disaggregated into local CA practices driven by indigenous knowledge and local innovations driven by NGO-led initiatives. Even though some of the CA innovations were not entirely new, their implementation was enhanced by NGOs. Figure 6 shows that mulching (layer of material applied to the surface of the soil to increase moisture) and mixed farming (a combination of livestock and crops on the same farm) were driven by indigenous knowledge. Actually, the preservation of traditional forms of farming knowledge and practices in Ghana helps to maintain biodiversity, enhance food security and protect natural resources.

Residue management (dropping of residue on farmlands) and organic manure (use of plant and animal manure on farms) were common practices of smallholder farmers in the study locations. Backyard gardening is also popular but the planting of cover crops is fading out of local farming systems. With regard to NGO-led CA practices, solar mechanisation (solar farming) was the least promoted CA technique. According to Adenle (2020) and Amankwah-Amoah (2015), solar mechanisation aims to accelerate the transformation of agriculture and food systems in Africa. The low promotion of solar farming in northern Ghana is probably due to the inability of most smallholder farmers to acquire and deploy

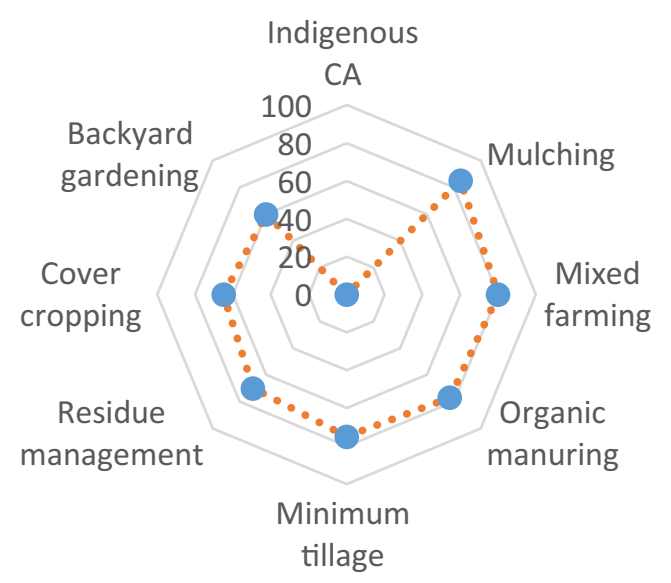

Fig. 6 Indigenous CA 
renewable energy technologies. However, this technology presents a great opportunity for transforming agriculture in the area. As is illustrated in Fig. 7, the promotion of agroforestry, rainwater harvesting and introduction of farmers to drought-tolerant crops are some of the principal CA practices promoted by NGOs.

The results of the field investigations also indicated that $\mathrm{CA}$ is backsliding in Ghana because of a number of fundamental challenges, including inadequate financial capacity (see Table 4). Obviously, attaining circularity in agriculture is expensive and particularly difficult to achieve from the initial stages in SSA countries like Ghana. A successful deployment of CA in the country requires education, capacity building, transfer of knowledge and technology, human resources and policy changes and/or adjustments. In 2019, Ghana estimated 150 million USD for financing sustainable agriculture and transforming the sector. However, about $95 \%$ of this budget was expected to come from foreign sources. As AssibeyYeboah (2019) and Donkor (2019) rightly pointed out, this financing strategy is likely to hinder the country from achieving her agriculture circularity ambitions. For example, agricultural practices like the use of fertiliser, waste water treatment, waste food management and bioenergy are too expensive for most agricultural value chain stakeholders, and in some cases, the relevant technologies are not available. Inadequate participation by the stakeholders is also a major obstacle to achieving the transition to CA in Ghana. For effective deployment of CE/CA in the country, the principle of industrial symbiosis must be operational to motivate action. The haphazard manner in which enterprises are located in the country makes industrial symbiosis difficult to realise. Moreover, most industries in the country have not fully realised the need to work together, to share information and resources. An industrial expert aptly captured the situation thus:

The $\mathrm{CE}$ concept is the best to achieve environmental and economic objectives. The challenge is the location of industries in the cities which makes it difficult for the system to operate. The industries are dispersed and

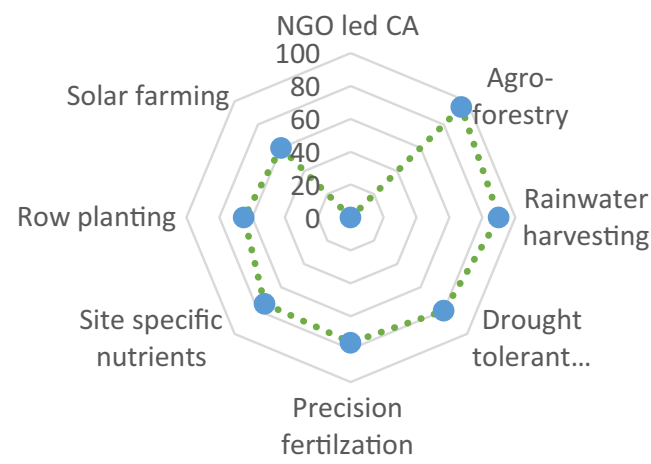

Fig. 7 NGO-led CA located several miles away from each other. Industrial operators feel reluctant to go for each other's waste because of the high transportation costs. The closer the location, the easier it would be for transfer of waste from industry to industry (interviewee 2; industrial expert).

Notwithstanding the myriad of challenges hindering Ghana's transition to CA, the majority of policy-makers and experts interviewed during the field survey acknowledged that the model has great potential to generate enormous economic, social and environmental benefits and thereby help to promote sustainable development in the country. The economic benefits derivable from the model include low cost of production and marketing of agricultural goods. Adapting the $6 \mathrm{R}$ principle will ensure an efficient and effective use of natural resources. For instance, agricultural waste from farms could be used by industries to produce organic fertiliser to facilitate intensification of agriculture. Again, livestock rearing can promote bioenergy production through methane capture and manure management and thereby provide cheaper sources of farm energy (Table 5).

In addition, agro-processing firms will be able to provide various forms of livelihood diversification for farmers and income generation opportunities. From a socio-cultural perspective, CA can effectively influence poverty reduction, food and nutrition security, empowerment of vulnerable groups, quality healthcare and social wellbeing. For example, Kapoor et al. (2020) and Toop et al. (2017) argue that circularity does not only focus on profitability but is very relevant for promoting wellbeing and sustainable development. The deployment of the CA model will help to improve agricultural value chains and provide ample opportunities for empowering vulnerable groups and the development of rural communities. A massive application of the CA principles in Ghana will also help to deliver significant environmental benefits such as sustainable management of natural resources, efficient waste

Table 4 Challenges faced by agricultural value chain stakeholders in Ghana

\begin{tabular}{|c|c|c|c|c|c|}
\hline Challenges & High & Moderate & Low & WAI & Rank \\
\hline Inadequate financial capacity & 31 & 2 & 1 & 1.72 & 1 \\
\hline Lack of CA technology & 29 & 2 & 2 & 1.42 & 2 \\
\hline Relatively new to the culture & 27 & 5 & 1 & 1.09 & 3 \\
\hline $\begin{array}{l}\text { Inadequate stakeholder } \\
\text { participation }\end{array}$ & 24 & 5 & 4 & 0.88 & 4 \\
\hline $\begin{array}{l}\text { Low level of government } \\
\text { investment }\end{array}$ & 22 & 8 & 3 & 0.54 & 5 \\
\hline $\begin{array}{l}\text { Inadequate education on the } \\
\text { concept }\end{array}$ & 19 & 10 & 4 & 0.42 & 6 \\
\hline
\end{tabular}

$W A I$ weighted average index 
Table 5 Benefits of CA

\begin{tabular}{llllll}
\hline & High & Moderate & Low & WAI & Rank \\
\hline Economic Benefits & & & & & \\
$\quad$ Low cost of productivity & 20 & 7 & 6 & 1.82 & 1 \\
Increase farmers income & 18 & 9 & 6 & 0.53 & 2 \\
Livelihood diversification & 16 & 10 & 7 & 0.52 & 3 \\
Promote saving culture among farmers & 13 & 11 & 9 & 0.32 & 4 \\
Social benefits & & & & & \\
$\quad$ Poverty reduction & 24 & 6 & 3 & 1.87 & 1 \\
Improve health and social wellbeing & 22 & 10 & 1 & 1.04 & 2 \\
Promote food security & 18 & 11 & 4 & 0.80 & 3 \\
$\quad$ Empowerment of vulnerable groups & 16 & 13 & 4 & 0.73 & 4 \\
Environmental benefits & & & & & \\
Natural resources protection & 27 & 3 & 3 & 1.72 & 1 \\
GHG emissions reduction & 25 & 4 & 2 & 1.22 & 2 \\
Waste management & 22 & 8 & 3 & 0.90 & 3 \\
\hline
\end{tabular}

WAI weighted average index

management and reduction in greenhouse gas (GHG) emissions. CA is projected to promote a carbon-neutral society and significant socio-economic development over the years. A non-governmental (NGO) representative interviewee had this to say:

For me, working in rural communities to empower farmers' circular agriculture activities has many benefits including increasing productivity, generating more income and keeping the environment clean. Yes, it is sometimes difficult for farmers to understand. However, connecting them with other value chain actors will enable them to easily operate within the circularity principles (interviewee 3; NGO expert).

\section{Conclusion and Policy Implications}

Circular agriculture (CA) is an express approach to transform economic growth and environmental sustainability in the world. CA presents ample opportunities for effective natural resources management and reduction in waste and pollution. Therefore, up-scaling and out-scaling CA principles in Ghana can significantly lead to socio-economic transformation of the country and motivate strong action on ensuring environmental sustainability. However, the results of the field survey conducted for writing this paper clearly indicated that achieving CA ambitions in Ghana may be complicated and hindered by the current limited stakeholders' knowledge of the concept as well as their inadequate financial capacity and low participation rate. The CA principles of reuse, refuse, rethink, repair and recycle are not well incorporated into the activities of agriculture value chain actors partly due to inadequate education on the concept. In other words, the practices of the linear economy model are still predominant in Ghana's agricultural sector. Without effectively promoting proper understanding and knowledge of the model and methods of deployment, it would be quasi impossible to achieve circularity in Ghana's agricultural sector and to enjoy the expected economic, social and environmental benefits. The key challenges hindering Ghana's transition to CA identified by the majority of the interviewees included inappropriate policies, inadequate human, institutional and financial capacities, lack of CA technologies and poor stakeholder participation. It is interesting to note that in a few areas where CA principles are effectively practised, maximum benefits were derived. For example, vegetable farmers in Navrongo in the Upper East Region are enjoying low cost of production, increased incomes and opportunities for livelihood diversification and preservation of biodiversity. In addition, the deployment of CA principles has positively influenced poverty reduction, improved health and social wellbeing, food security and empowerment of agricultural stakeholders in a number of communities in the study locations.

In order to redress these challenges, it is necessary to scale up the deployment of the concept and its practices through well-thought-out policy, strategies and concrete actions on the ground. First of all, the existing top-down approaches to agriculture and national development should be replaced by appropriate bottom-up strategies across all regions in the country. Adapting bottom-up approaches to create awareness across the entire agricultural value chains in the country and increase financial investment in the sector needs to be broadened and made more attractive. In addition, it is recommended that the government, civil society organisations and NGOs should intensify their education and capacity building programmes on the deployment of CA in the country. The 
CA model should be presented as a comprehensive national sustainable development paradigm and the private sector, civil society organisations and individuals in the country actively encouraged and incentivised to apply the model and ensure the realisation of the expected economic, social and environmental benefits for the population. Existing traditional agricultural practices such as agroforestry, crop rotation, mixed-/ inter-cropping, polyculture and water harvesting will help to facilitate the deployment of CA in Ghana. Finally, accelerating the country's transition to CA and establishing a sustainability trajectory require vibrant international collaborations that ensure the transfer of appropriate technologies and technical assistance supports agricultural value chain stakeholders.

While this paper generated interesting findings, it has a number of inherent limitations that should be addressed by future researchers working on the subject. The paper's first principal limitation is its exploratory nature and limited geographical scope to northern Ghana. These two constrains make generalisation of the results of the paper to the whole country unrealistic. Secondly, the non-availability of data on CA practices in the study locations did not permit rigorous quantitative analysis. Most of the agricultural value chain stakeholders including the agro-processing enterprises did not have databases on their operations. It is therefore recommended that in-depth cross-sectional and comparative studies should be conducted in the country to establish the knowledge on CA and to broaden its deployment across the value chains of the principal agricultural crops and products.

Acknowledgements Open Access funding provided by Projekt DEAL. The authors hereby wish to acknowledge the active assistance of Mr. Benedict A. Dibkuu, the Project Manager of the Northern Sector Office of International Centre for Enterprise and Sustainable Development (ICED) - which is headquartered in Accra, Ghana - in the collection of data in the Upper West Region for the preparation of this paper. We also extend our appreciation to all the agricultural stakeholders who participated in the field survey.

Open Access This article is licensed under a Creative Commons Attribution 4.0 International License, which permits use, sharing, adaptation, distribution and reproduction in any medium or format, as long as you give appropriate credit to the original author(s) and the source, provide a link to the Creative Commons licence, and indicate if changes were made. The images or other third party material in this article are included in the article's Creative Commons licence, unless indicated otherwise in a credit line to the material. If material is not included in the article's Creative Commons licence and your intended use is not permitted by statutory regulation or exceeds the permitted use, you will need to obtain permission directly from the copyright holder. To view a copy of this licence, visit http://creativecommons.org/licenses/by/4.0/.

\section{References}

Adenle AA (2020) Assessment of solar energy technologies in Africaopportunities and challenges in meeting the 2030 agenda and sustainable development goals. Energy Policy 137:111180
Adzawla W, Kane A (2019) Effects of climate shocks and climate adaptation through livelihood diversification on gendered welfare gaps in northern Ghana. Int J Environ Clim Chang 9(2):104-119

Africa Union (2015) African Union's strategic plan for the Ecological Organic Agriculture Initiative (OEA) from 2015 to 2025, African Union Decision EX.CL/Dec.621XVIII

AgroCycle (2017) The 'circular economy' applied to the agri-food sector, Presented at the European Commission DG Research and Innovation hosted Conference on: 3Harnessing Research and Innovation for FOOD 2030: a Science Policy Dialogue, 16 October 2017, Brussels. Retrieved from www.agrocycle.eu on 10 February 2019

Alliance for a Green Revolution in Africa (AGRA) (2014), Africa Agriculture Status Report 2014: climate change and smallholder agriculture in Sub Saharan Africa, http://hdl.handle.net/10568/ 42343

Amankwah-Amoah J (2015) Solar energy in Sub-Saharan Africa: the challenges and opportunities of technological leapfrogging. Thunderbird Int Bus Rev 57(1):15-31

Antoniou N, Monlau F, Sambusiti C, Ficara E, Barakat A, Zabaniotou A (2019) Contribution to circular economy options of mixed agricultural wastes management: coupling anaerobic digestion with gasification for enhanced energy and material recovery. J Clean Prod 209:505-514

Assibey-Yeboah MD (2019) Report of the finance committee on the annual budget estimates for the Ministry of Finance for the 2020 financial year. Accra, Ghana

Berg A, Antikainen R, Hartikainen E, Kauppi S, Kautto P, Lazarevic D, Spiesik S, Saikku L (2018) Circular economy for sustainable development. The Finnish Environmental Institute, Helsinki, Finland

Boadi SA, Owusu K (2019) Impact of climate change and variability on hydropower in Ghana. African Geographical Review 38(1):19-31

Canning D, Raja S, Yazbeck AS (2015) Africa's demographic transition: dividend or disaster? The World Bank, Washington D.C., USA

Cheng H, Dong S, Li F, Yang Y, Li Y, Li Z (2019) A circular economy system for breaking the development dilemma of 'ecological Fragility-Economic poverty'vicious circle: A CEEPS-SD analysis. Journal of Cleaner Production, 212, 381-392

da Silva CL (2018) Proposal of a dynamic model to evaluate public policies for the circular economy: Scenarios applied to the municipality of Curitiba. Waste Management, 78, 456-466

Donkor K (2019) Structural adjustment and mass poverty in Ghana. Routledge, London, United Kingdom

Ellen MacArthur Foundation (2013) Towards the circular economy: opportunities for the consumer goods industry. Retrieved from www. ellenmacarthurfoundsation.org/2013.pdf; 30 June 2019

Ellen MacArthur Foundation (2015) Growth within: A Circular Economy Vision for a Competitive Europe. Ellen MacArthur Foundation, Isle of Wight, UK.

Ellen MacArthur Foundation (2019) What is circular economy? Retrieved from www.ellenmacarthurfoundation.org/what-iscircular-economy; 4 May 2019

European Commission (2015) Commission work programme - key documents. https://ec.europa.eu/info/publications/workprogrammecommission-key-documents-2015 en, March 2020

Europen Union (2019) Circular Economy opportunities in Ghana, Conference Report, 2-8 May 2019. Retrieved from Seminar\%20o\%20Circular\%20Economy\%in\%20Africa\%20Final\%20Report.pdf; 18 June 2019

Falola, T., \& Mbah, E. M. (2014) Introduction: Change and continuity in contemporary Africa. In Contemporary Africa (pp. 1-19). Palgrave Macmillan, New York, Introduction

FAO (2016) The state of food and agriculture: climate change. Agriculture and Food Security, FAO, Rome, Italy

FAO (2017) SAVE FOOD: global food initiative on food loss and wastage reduction. Retrieved from www.fao.org/save-food/regional/ europeanunion/en/; 30 June 2019 
Food Aid Foundation (2019) Hunger statistics. Retrieved from www. foodaidfoundation.org/world-hunger-statistics/html, 28 May 2019

Food and Agriculture Organization (2011) Global food losses and food waste: extent, causes, and prevention. FAO, Rome, Italy

Geisendorf S, Pietrulla F (2017) The circular economy and circular economic concepts-a literature analysis and redefinition. Thunderbird International Business Review 60:771-782. https://doi.org/10.1002/ tie. 21924

Ghana Meteorological Agency (2016) Regional Weather Forecast. Retrieved from https://www.meteo.gov.gh/gmet/regional-weather/, January 2020.

Ghisellini P, Cialani C, Ulgiati S (2016) A review on circular economy: the expected transition to a balanced interplay of environmental and economic systems. J Clean Prod 114:11-32

Hanumante NC, Shasti Y, Hoadley A (2019) Assessment of circular economy for global sustainability using an integrated model. Resour Conserv Recycl 151:104460

Issahaku G, Abdulai A (2019) Can farm households improve food and nutrition security through adoption of climate-smart practices? Empirical evidence from Northern Ghana. Applied Economic Perspectives and Policy

Jawahir IS, Dillon Jr OW, Kunal JJ, Anand V, Israd HJ (2006) $10^{\text {th }}$ International Research/Expert Conference "Trends in the development of machinery and associated technology" TMT, BarcelonaLloret de Mar, Spain, 11-15 September, 2006

Junjie CAO, Ming LI, Shuguo LI (2011) Development strategy research of modern eco-agriculture on the basis of constructing the rural circular economy - for the example of Shandong Province. Energy Procedia 5:2504-2508

Kapoor R, Ghosh P, Kunar M, Sengupta S, Gupta A, Kumar SS, Pant D (2020) Valorization of agricultural waste for biogas based circular economy in India: a research outlook. Bioresource Technol:123036

Kyei-Mensah C, Kyerematen R, Adu-Acheampong S (2019) Impact of rainfall variability on crop production within the Worobong Ecological Area of Fanteakwa District, Ghana. Adv Agric 2019

Lopes C, Kararach G (2019) Structural change in Africa: misperceptions, new narratives and development in the 21 st century. Routledge

Lovins H (2019) Circular principles for healthy agriculture. Retrieved from www.greenbiz.com/article/3-circular-principles-healthyagriculture, 11 February 2019

McKinsey C (2016) The circular economy: moving from theory to practice. McKinsey Centre for Business and Environment, Special edition, October 2016

Murray, A. et al. (2017) The circular economy: an interdisciplinary exploitation of the concept and application in a global context. Journal of Business Ethics, February 2017, Volume 140, Issue 3, pp369-380

Nkrumah F, Klutse NAB, Adukpo DC, Owusu K, Quagraine KA, Owusu A, Gutowski W (2014) Rainfall variability over Ghana: model versus rain gauge observation. Int J Geosci 5(7):673-683

Nunfam VF, Oosthuizen J, Adusei-Asante K, Van Etten EJ, Frimpong K (2019) Perceptions of climate change and occupational heat stress risks and adaptation strategies of mining workers in Ghana. Sci Total Environ 657:365-378

Nyamadi BV, Minta A, Darghout S, Bullock A, Denison J, Agodzo S, Namara R (2012) Ghana agricultural water management investment framework, ministry of food and agriculture. Accra, Ghana

OECD, FAO (2016) Agriculture in Sub-Saharan Africa: prospects and challenges for the next decade, in OECD-FAO agricultural outlook 2016-202

Okoye CU, FLEAD F (2016) Institution building for grassroots community and rural development in Nigeria: dominant themes. Opportunities and Challenges

Parry ML (2019) Climate change and world agriculture. Routledge

Saidani, M., Leroy Y., Cluzel, F. and Kendall, A. (2019) A taxonomy of circular economy indicators, Journal of Cleaner Production, Elsevier, 2019, 207, pp542-559
Schroeder P, Anggraeni K, Weber U (2019) The relevance of circular economy practices to the sustainable development goals. J Ind Ecol 23(1):77-95

Secco C, da Luz LM, Pinheiro E, Puglieri FN, Piekarski CM, de Francisco AC, Freire FMCS (2020) Circular economy in the pig farming chain: proposing a model for measurement. J Clean Prod 121003

Simone D, Livio D, Popoff F (2000) World Business Council for Sustainable Development: Eco-efficiency: The Business Link to Sustainable Development

Stahel WR (2013) Policy for material efficiency - sustainable taxation as a departure from the throwaway society. Philosophical Transactions ofthe Royal Society A: Mathematical, Physical and Engineering Sciences, 371(1986), 20110567

Swilling M (2019) Growth, sustainability and dematerialisation: resource use options for South Africa 2019. In Paper commissioned by the Presidency, South African Government, presented at a Workshop on Scenarios for

The World Bank (2013) Unlocking Africa's agricultural potential, The World Bank, Washington D.C. Retrieved from: https://documents. worldbank.org/curated/en/327811467990084951/pdf/ 756630v10REPLA0frica0pub03011013web.pdf, 27 May 2019

Thiaw I (2017) What role can circular economy play in delivering the Paris Agreement? Institute for European Environment Development Policy, 11 December 2017. Retrieved from: https://ieep.eu/news/ what-role-can-circulare-economy-play-in-delivering-the-parisagreement, 7 May 2019

Toop TA, Ward S, Oldfield T, Hull M, Kirby ME, Theodorou, MK (2017) AgroCycle-developing a circular economy in agriculture. Energy Procedia 123:76-80

United Nations (2015) UN Climate Change Conference Paris 2015. Retrieved from https://www.un.org/sustainabledevelopment/cop21/, March 2015

Veolia (2018) How do we feed (billion in 2040? Retrieved from: www. veolia.com/en/newsroom/press-day-2018/how-do-we-feed-9billion-people-in-2040, 10 February 2019

Veras, O. (2017) Agriculture in Africa: potential versus reality. Retrieved from: www.howwemadeitinafrica.com/egypt-investors-flpping-newpropert-developments-within-30-days/57624/, 14 February 2019

Wageningen University, Research Centre (2018) Circular agriculture: a new perspective for Dutch agriculture. Retrieved from: www.wur. nl/en/newsarticle/Circular-agriculture-a-new-perspective-forDutch-agriculture-1.html, 5 May 2019

WEF (2014) World Economic Forum Annual Meeting. https://www. weforum.org/events/world-economic-forum-annual-meeting-2014, April 2020

Wijkman, A. and Skånberg, K. (2016) The circular economy and benefits for society, jobs and climate. Retrieved from www.clubofrome.org/ wp-content/uploads/2016/03/The Circular-Economy-and-Benefitsfor-Society.pdf, 27 May 2019

World Food Programme (2019) Global Report on Food Crises: acute hunger still affecting over 100 million people worldwide. Retrieved from http://www.fao.org/news/story/en/item/1187744/ icode/, January 2020

Wrigley-Asante C, Owusu K, Egyir IS, Owiyo TM (2019) Gender dimensions of climate change adaptation practices: the experiences of smallholder crop farmers in the transition zone of Ghana. African Geographical Review 38(2):126-139

Wyman O (2017) Supporting the circular economy transition: the role of the financial sector in the Netherlands. Retrieved from www. oliverwyman.com/content/dam/oliver-wyman/v2/publications/ 2017/sep/CircularEconomy_print.pdf, 4 February 2019

Xi H (2011) Models of circular economy on agriculture in Yunnan Province. Energy Procedia 5:1078-1083

Zucchella A, Previtali P (2019) Circular business models for sustainable development: a "waste is food" restorative ecosystem. Bus Strateg Environ 28(2):274-285 